Article

\title{
In Silico/In Vitro Hit-to-Lead Methodology Yields SMYD3 Inhibitor That Eliminates Unrestrained Proliferation of Breast Carcinoma Cells
}

\author{
Ilham M. Alshiraihi ${ }^{1,2}{ }^{10}$, Dillon K. Jarrell ${ }^{3}$, Zeyad Arhouma ${ }^{1,4}{ }^{,}$Kelly N. Hassell ${ }^{1}$, \\ Jaelyn Montgomery ${ }^{5}$, Alyssa Padilla ${ }^{5}$, Hend M. Ibrahim ${ }^{6,7,8}$, Debbie C. Crans ${ }^{1,4}$, \\ Takamitsu A. Kato 1,7 (D) and Mark A. Brown 1,8,9,10,11,* \\ 1 Cell and Molecular Biology Program, Colorado State University, Fort Collins, CO 80523-1005, USA; \\ alshiraihi@gmail.com (I.M.A.); zkrahuma@rams.colostate.edu (Z.A.); khassell@colostate.edu (K.N.H.); \\ debbie.crans@colostate.edu (D.C.C.); tkato@rams.colostate.edu (T.A.K.) \\ 2 Department of Biology, University of Tabuk, Tabuk 47713, Saudi Arabia \\ 3 Department of Bioengineering, University of Colorado Anschutz Medical Campus, \\ Aurora, CO 80045-7109, USA; dillom.jarrel@cuanschutz.edu \\ 4 Department of Chemistry, Colorado State University, Fort Collins, CO 80523-1872, USA \\ 5 Department of Biomedical Sciences, Colorado State University, Fort Collins, CO 80523-1617, USA; \\ Jaelyn.Montgomery@rams.colostate.edu (J.M.); aepad20@rams.colostate.edu (A.P.) \\ 6 Department of Medical Biochemistry, Zagazig University, Zagazig 44511, Egypt; hendibrahim1@gmail.com \\ 7 Department of Environmental \& Radiological Health Sciences, Colorado State University, \\ Fort Collins, CO 80523-1618, USA \\ 8 Department of Clinical Sciences, Colorado State University, Fort Collins, CO 80523-1678, USA \\ 9 Epidemiology Section, Colorado School of Public Health, Fort Collins, CO 80523-1612, USA \\ 10 Institute for Learning and Teaching, Colorado State University, Fort Collins, CO 80523-1052, USA \\ 11 Department of Ethnic Studies, Colorado State University, Fort Collins, CO 80523-1790, USA \\ * Correspondence: mark.brown@colostate.edu
}

Received: 30 October 2020; Accepted: 11 December 2020; Published: 15 December 2020

\begin{abstract}
SMYD3 is a lysine methyltransferase that regulates the expression of over 80 genes and is required for the uncontrolled proliferation of most breast, colorectal, and hepatocellular carcinomas. The elimination of SMYD3 restores normal expression patterns of these genes and halts aberrant cell proliferation, making it a promising target for small molecule inhibition. In this study, we sought to establish a proof of concept for our in silico/in vitro hit-to-lead enzyme inhibitor development platform and to identify a lead small molecule candidate for SMYD3 inhibition. We used Schrodinger ${ }^{\circledR}$ software to screen libraries of small molecules in silico and the five compounds with the greatest predicted binding affinity within the SMYD3 binding pocket were purchased and assessed in vitro in direct binding assays and in breast cancer cell lines. We have confirmed the ability of one of these inhibitors, Inhibitor-4, to restore normal rates of cell proliferation, arrest the cell cycle, and induce apoptosis in breast cancer cells without affecting wildtype cell behavior. Our results provide a proof of concept for this fast and affordable small molecule hit-to-lead methodology as well as a promising candidate small molecule SMYD3 inhibitor for the treatment of human cancer.
\end{abstract}

Keywords: hit-to-lead; in silico drug development; SMYD3; methyltransferase; Inhibitor-4; breast cancer; cell proliferation; cell cycle; apoptosis

\section{Introduction}

SMYD (SET and MYND domain-containing) protein family members constitute a class of methyltransferases that regulate a wide range of normal cellular processes [1-3] and are also involved 
in several tumorigenic pathways [3-5]. SMYD3, the third member of the SMYD family, transfers methyl groups to lysine 4 on histone $\mathrm{H} 3$ (H3K4) and lysine 5 on histone 4 (H4K5), a residue that was previously thought to only undergo acetylation [1-3]. Overexpression of SMYD3 results in increased cell proliferation and activates many genes associated with cancer cell transformation [6] and metastasis [7]. Several studies have revealed that lung, breast, pancreatic, colorectal, and hepatocellular carcinoma are highly associated with SMYD3 overexpression [3,8,9]. In vitro studies using NIH3T3 cells have demonstrated that SMYD3 involvement in uncontrolled proliferation is one of the crucial stages in tumorigenesis. Furthermore, the growth of breast, hepatocellular, and colorectal carcinoma cell lines have been impaired significantly through SMYD3 knockdown $[3,8]$. These studies demonstrate that the oncogenic impact of SMYD3 is mediated in part by its histone methylation activity and the resulting impact on the expression of oncogenes. These downstream genes include NKX2.8 [3], WNT10B [8], TERT [10], cMET [11], and CDK2 [12]. SMYD3 is also known to regulate cancer cell proliferation and viability through its interaction with vascular endothelial growth factor receptor 1 (VEGFR1) [13] and estrogen receptor (ER) [14], both of which are non-histone proteins. The role of SMYD3 in ER-mediated transcription through its histone methyltransferase activity is not fully known. SMYD3 acts as a cofactor of ER $\alpha$ and promotes its efficacy in response to bound ligands. In addition, SMYD3 interacts with ER in the ligand binding domain and activates the transcriptional machinery of downstream genes [14]. Collectively, these studies indicate SMYD3 as a potential therapeutic target for cancer treatment.

The small molecule drug development process is notoriously expensive, time consuming, and inefficient. After target identification, identifying hit compounds with significant activity requires enormous small-molecule libraries and hours of experimentation. Optimizing hit compounds to identify leads that have activity in cells and that meet initial in vitro toxicity criteria often requires several rounds of iteration and molecular synthesis. Because of the difficulty and cost of this process, scientific literature is saturated with studies that identify proteins that are "promising therapeutic targets" but that proceed no further towards actual therapeutic development. In this study, we sought to establish a simple and affordable hit-to-lead methodology that could be implemented by average research laboratories that have elucidated druggable proteins. Using in silico screening to identify initial hits and restricting the initial library to purchasable compounds, we implemented the Small Molecule Drug Discovery Suite (Schrodinger, Inc., NY, USA) to predict the binding affinity of a library of 137,990 molecules [15-17] and thus have demonstrated the ability to identify lead small molecule inhibitors without the need for physical compound libraries or in-house chemical synthesis.

Using SMYD3 as a target protein, we implemented our screening methodology and report a novel small molecule SMYD3 inhibitor (Inhibitor-4) that impairs breast cancer cell proliferation without affecting normal cells, illustrating the potential of SMYD3 inhibitors in the clinical management of breast cancer as well as a proof of concept for this drug development platform. We used two breast cancer cell lines (MCF7 and MDA-MB-231) that were previously shown to overexpress SMYD3 [8,14,18-20] compared with the wild type breast epithelial cell line MCF10A [18,19] (Table 1). After initial hit identification in vitro, we purchased and tested five novel small molecule SMYD3 inhibitors and discovered that Inhibitor-4 significantly reduces breast cancer proliferation, arrests the cell cycle, and induces apoptosis without impacting wild type cells. In all experiments, we used a previously-identified SMYD3 small molecule inhibitor, BCI-121, as a positive control [21].

Table 1. Summary of SMYD3 availability and activity in the cell lines used in this study.

\begin{tabular}{cccccc}
\hline $\begin{array}{c}\text { Cancer Cell } \\
\text { Lines }\end{array}$ & Origin & $\begin{array}{c}\text { SMYD3 } \\
\text { Expression }\end{array}$ & Assay & $\begin{array}{c}\text { Methylation } \\
\text { Activity }\end{array}$ & References \\
\hline $\begin{array}{c}\text { MCF7/MDA- } \\
\text { MB-231 }\end{array}$ & $\begin{array}{c}\text { Human epithelial } \\
\text { breast cancer cells }\end{array}$ & High & $\begin{array}{c}\text { Western blot, } \\
\text { RT-qPCR }\end{array}$ & H4K5, H3K4 & {$[8,14,18-20]$} \\
\hline MCF10A & $\begin{array}{c}\text { Human epithelial } \\
\text { breast cells }\end{array}$ & Very low & $\begin{array}{c}\text { Western blot, } \\
\text { RT-qPCR }\end{array}$ & H4K5, H3K4 & {$[18,19]$} \\
\hline
\end{tabular}




\section{Results}

\subsection{Inhibitor-4 Decreases SMYD3-Mediated H3 Methylation}

After our iterative in silico screening using Schrodinger software (Glide ${ }^{\circledR}$, Maestro ${ }^{\circledR}$, LigPrep ${ }^{\circledR}$, and Epik $\left.{ }^{\circledR}\right)$, we purchased the top five hit compounds for testing. Hits were defined as the drug-like small molecules with the lowest free binding energy when docked in the protein-target binding pocket of SMYD3. The predicted free binding energies of the five lead compounds ranged from $-7.2 \mathrm{~kJ} / \mathrm{mol}$ to $-9.1 \mathrm{~kJ} / \mathrm{mol}$, compared to the natural protein ligand's predicted free binding energy of only around $-1 \mathrm{~kJ} / \mathrm{mol}$ (fragment of VEGFR1). We used an in vitro methylation assay using purified Histone 3 (H3) to assess the ability of the five lead in silico-designed SMYD3 inhibitor candidates to decrease SMYD3 enzymatic activity. We demonstrated that Compound 4 (Inhibitor-4) significantly reduces SMYD3-mediated Histone 3 methylation (70\% reduction), while the other novel compounds did not show significant differences. H3 was chosen because of previous studies that demonstrated SMYD3 methylates H3 preferentially (Figure 1) [3].

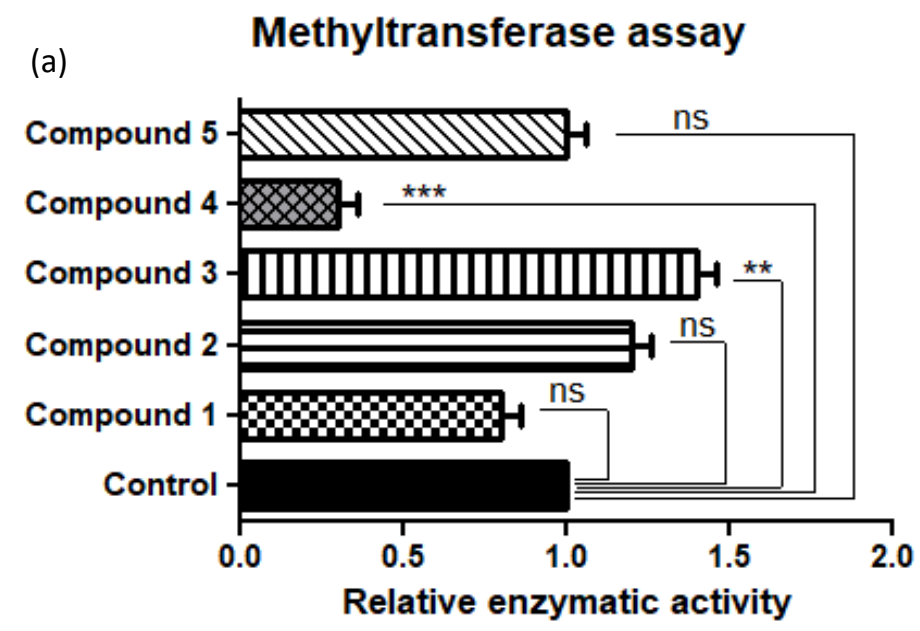

(b)

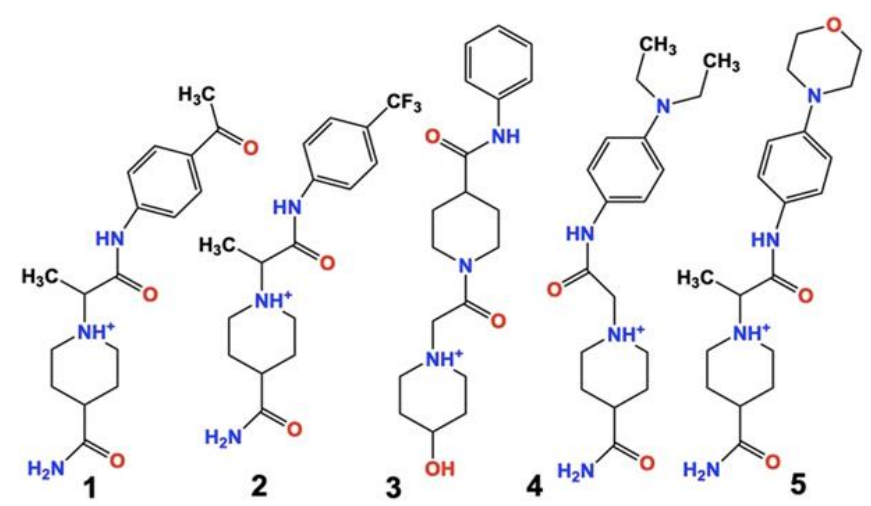

Figure 1. (a) Relative SMYD3 activity (top) with the top 5 candidates from in silico testing (bottom) using an in vitro methyltransferase assay (Colorimetric assay). (b) Compounds $1-5$ drawn in ChemDraw. Compound 4 is from here on referred to as Inhibitor- 4 . Error bars display standard error of means. Statistically significant differences from control are indicated by ${ }^{* *} p<0.01,{ }^{* * *} p<0.001$ or ns $p>0.05$.

\subsection{Inhibitor-4 and $B C l-121$ are Stable in $d_{6}$-DMSO Solution}

Because of the limited solubility of selected molecules in aqueous solution and in media, we dissolved BCI-121 and Inhibitor- 4 in $\mathrm{d}_{6}$-DMSO solution to record and analyze the $1 \mathrm{D}^{1} \mathrm{H}$ NMR spectra of both compounds. The major species attributed to Inhibitor-4 and BCI-121 were observed at time 0 and 24 h, as shown in Figure S1a (BCI-121) and Figure S1b (Inhibitor-4). The ${ }^{1} \mathrm{H}$ NMR peaks of the fresh and aged samples for Inhibitor- 4 showed no observable difference in the presence of the 
major component (67\%) and minor component (33\%) peaks as a function of time, suggesting that no hydrolysis is taking place during the experiment for Inhibitor- 4 . For BCI-121, $70 \%$ of the major species was present at time 0 , however after $24 \mathrm{~h}$ this decreased slightly to $68 \%$, suggesting that the positive control may be slightly less stable than Inhibitor-4.

\subsection{SMYD3 Is Overexpressed in Breast Cancer Cells}

Western blot and immunocytochemistry were carried out to test the expression levels of SMYD3 using anti-SMYD3 antibody in normal and breast cancer cell lines. Western blot data have indicated that SMYD3 was highly expressed in breast cancer cell lines (1.8-fold in MCF7 and 2.6-fold in MDA-MB-231) compared to normal cell line (Figure 2).

(a)

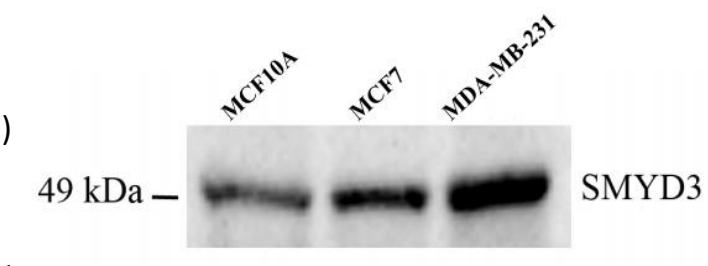

(b)

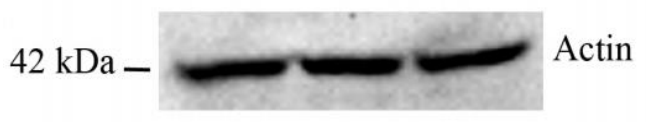

(c)
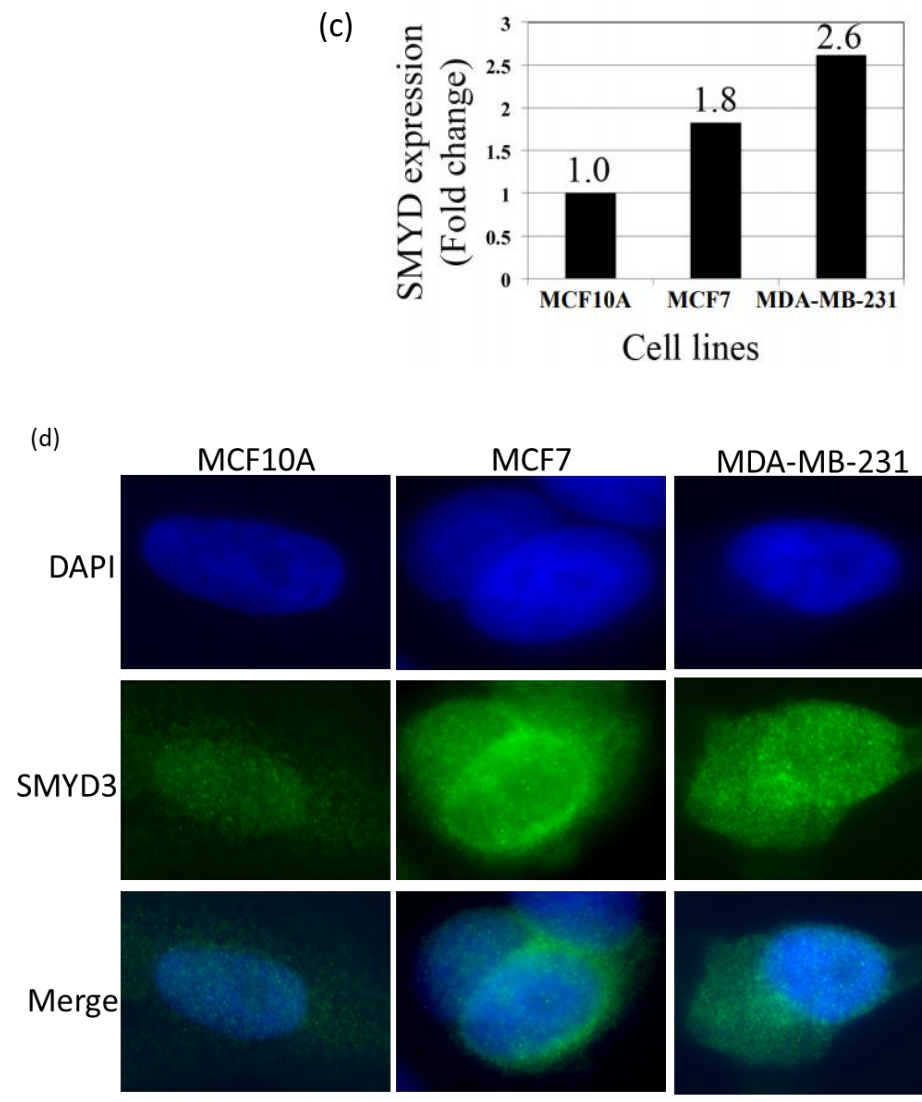

MDA-MB-231

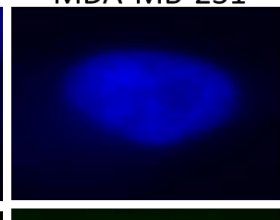

(e)
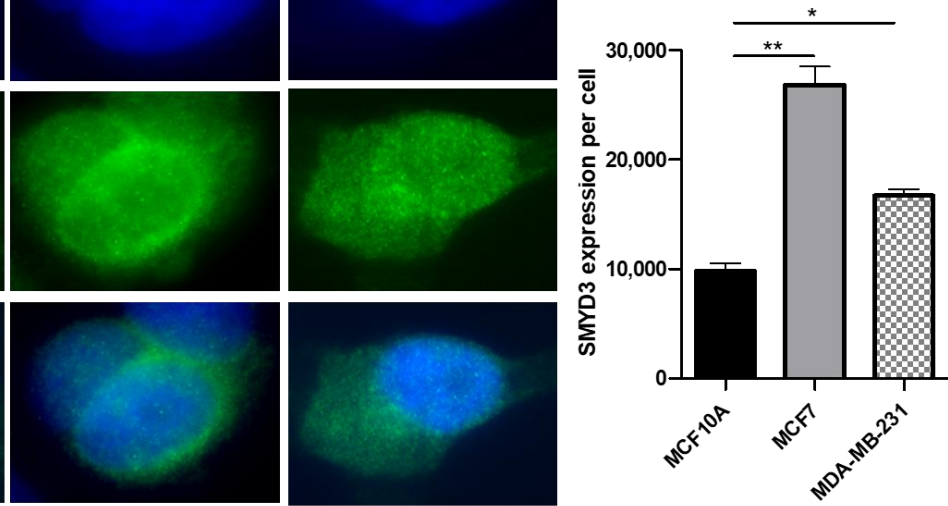

Figure 2. SMYD3 expression using western blot and immunocytochemistry: (a) Expression of SMYD3 protein in human cell lines using Western blot. (b) Expression of actin served as a quantitative control. (c) Western blot analysis shows fold change in SMYD3 expression in the cell lines. (d) Expression of SMYD3 protein using immunocytochemistry. (e) immunocytochemistry analysis shows SMYD3 intensity in the cell lines. Values are mean \pm standard error of the means. Statistically significant differences from control are indicated by ${ }^{*} p<0.05,{ }^{* *} p<0.01$. 
Additionally, immunocytochemistry data have shown elevated levels of SMYD3 expression in breast cancer cell lines comparing to normal cell line (Figure 2a,b). Therefore, increased SMYD3 expression could be correlated with breast carcinogenesis.

\subsection{Inhibitor-4 Inhibits Growth of Breast Cancer Cells}

The impact of SMYD3 inhibitors on growth of breast cancer cells was tested by adding 50, 100 and $200 \mu \mathrm{M}$ of Inhibitor-4 or BCI-121 to breast cancer cell lines (MCF7 and MDA-MB-231) and normal breast epithelial cell line (MCF10A). The number of cells was determined daily and the population doubling times were quantified (Figure 3). For MCF7 (breast cancer) cells, the basal doubling time for MCF7 was $38 \mathrm{~h}$, while $40 \mathrm{~h}$ for MDA-MB-231. Using the positive control inhibitor, a concentration of $200 \mu \mathrm{M}$ caused approximately 2-fold suppression of MCF7 cellular growth (Figure 3a). Using Inhibitor-4, however, a clear dose-dependent suppression in growth was observed with the first significant reduction observed at a concentration of $50 \mu \mathrm{M}$ (Figure 3b). In the MDA-MB-231 cell line, a significant delay in the cellular growth was observed with $200 \mu \mathrm{M}$ BCI-121 and only $50 \mu \mathrm{M}$ Inhibitor-4 (Figure 3c,d).

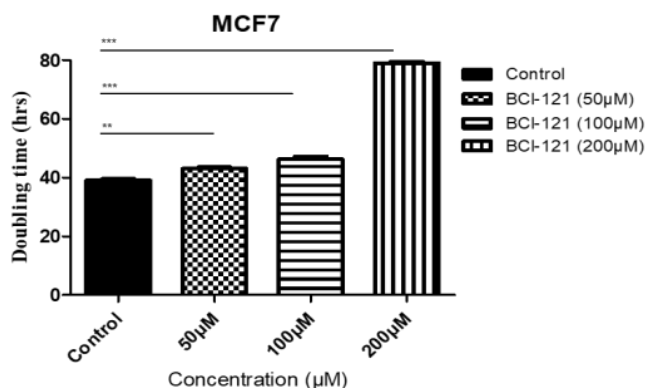

(a)

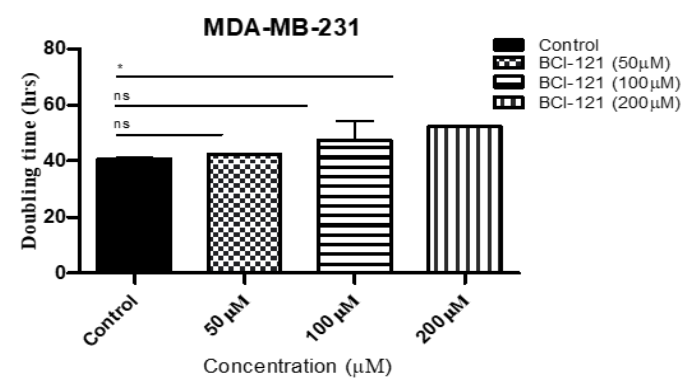

(c)

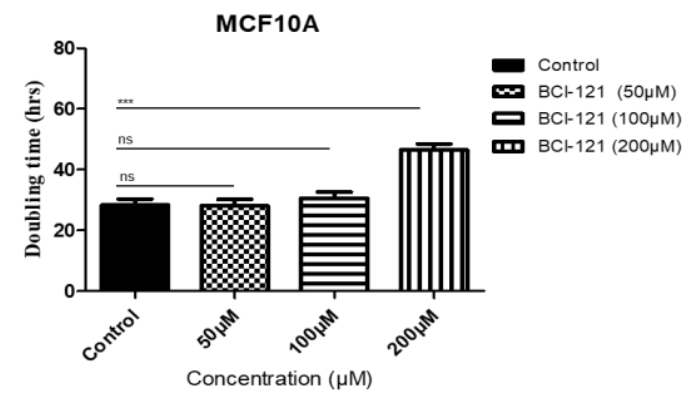

(e)

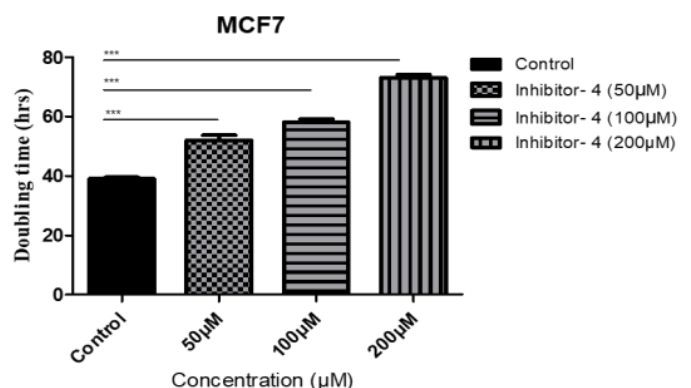

(b)

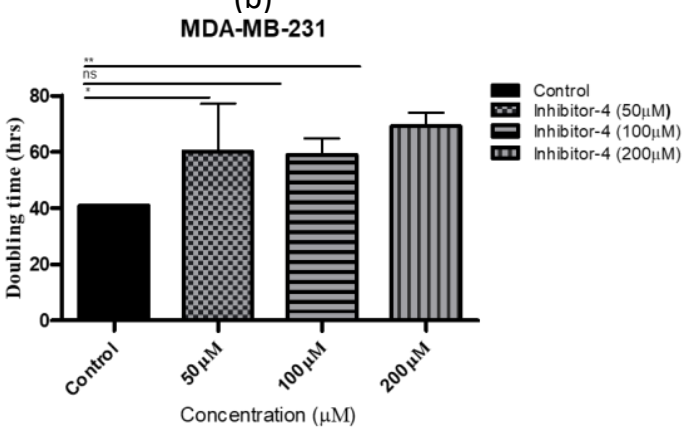

(d)

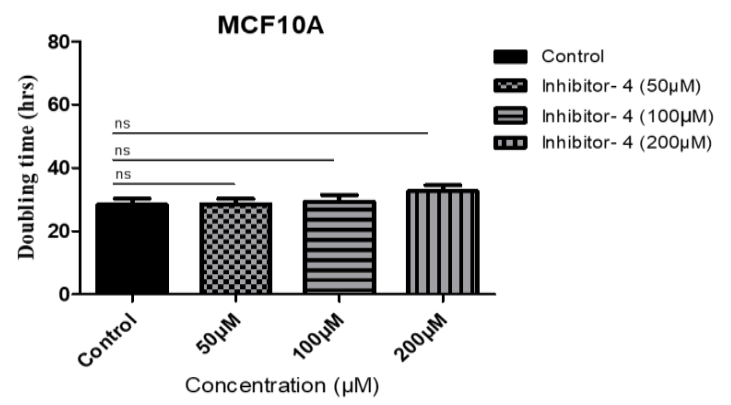

(f)

Figure 3. Cell population doubling time with SMYD3 inhibitor treatment. (a,c,e) Cells with BCI-121 as a positive control inhibitor. $(\mathbf{b}, \mathbf{d}, \mathbf{f})$ Cells with SMYD3 Inhibitor-4. Values are mean \pm standard error of the means. Statistically significant differences from control are indicated by ${ }^{*} p<0.05, * * p<0.01$, *** $p<0.001$ or ns $p>0.05$.

For MCF10A (normal) cells, the effect of the SMYD3 inhibitors was limited. The basal doubling time for MCF10A was $28 \mathrm{~h}$. Interestingly, no delay was noticed with 50, or $100 \mu \mathrm{M}$ concentrations 
of either inhibitor. Treatment of the normal cells with $200 \mu \mathrm{M}$ of Inhibitor-4 resulted in a minor, not significant, growth delay (approximately 5\%), while treatment with $200 \mu \mathrm{M} \mathrm{BCI}-121$ resulted in a major growth delay (Figure 3e,f). These results suggest that Inhibitor-4 shows more growth inhibition than BCI-121 and causes significant inhibition in cancer cell growth while only modestly impacting healthy cells.

\subsection{Inhibitor-4 Suppresses Breast Cancer Cell Colony Formation}

To determine the effects of Inhibitor- 4 on the colony formation of breast cancer cells and normal cell lines, the cells were treated with various concentrations of Inhibitor-4 and BCI-121 (10, 50, 100, 150 and $200 \mu \mathrm{M}$ ) and incubated for 2 weeks. Treatment with Inhibitor-4 significantly suppressed clonogenic activity in MCF7 and MDAMB-231 cells at concentrations of 50, 100, 150 and $200 \mu \mathrm{M}$ (Figure S2b,d) compared to normal MCF10A cell line (Figure S2f). Similarly, BCI-121 suppressed colony formation on MCF7 at nearly all concentrations (Figure S2a) and MDA-MB-231 cells at 150 and $200 \mu$ M concentrations (Figure S2c). Surprisingly, a significant decrease in colony formation of MCF10A (normal) cells was also observed at $200 \mu \mathrm{M}$ concentration of BCI-121 (Figure S2e) compared to Inhibitor 4, which did not affect MCF10A survival (Figure S2f). This result again suggests the improved inhibition effect of Inhibitor-4 compared to BCI-121.

\subsection{Inhibitor-4 Reduces Cell Viability in MCF7 Cells}

The effect of Inhibitor- 4 on the viability of wild type and cancer cell lines was evaluated using an MTT assay at different time points $(24,48,72$, and $96 \mathrm{~h}$ ). Cells were treated with the vehicle (DMSO $0.1 \%, 0.15 \%$ and $0.2 \%$ ), BCI-121, or Inhibitor-4 (Figure S3). Treatment with BCI-121 caused significant decreases in cell viability in both breast cancer (MCF7 and MDA-MB-231) and wild type (MCF10A) cell lines at multiple time points, particularly at concentrations of 150 and $200 \mu \mathrm{M}$ (Figure S3a,c,e). However, Inhibitor-4 caused significant decreases in cell viability only in the cancer cell lines (MCF7 at 150 and $200 \mu \mathrm{M}$, MDA-MB-231 at $200 \mu \mathrm{M}$; Figure S3b,d). No concentration of Inhibitor-4 impacted MCF10A cellular viability (Figure S3f). Collectively, these data suggest that Inhibitor-4 is a promising, cancer-specific inhibitor that reduces cancer cell line viability and growth without affecting normal cells.

\subsection{Inhibitor-4 Induces Cell Cycle Arrest in Breast Cancer Cells}

To investigate whether the growth inhibitory effect of Inhibitor-4 on breast cancer cells was due to cell cycle arrest, we conducted cell cycle analysis using Propidium Iodide (PI) staining. Cells were treated with $200 \mu \mathrm{M}$ of BCI-121 or Inhibitor- 4 for $24 \mathrm{~h}$. As shown in Figure 4 and Figure S4, treatments with both the positive control inhibitor and Inhibitor-4 induced G1 arrest and reduced S phase in MCF7 cells (Figure S4b,c and Figure 4a,b) compared to MCF7 control (Figure S4a). Also, both treatments led to G1 arrest in MDA-MB-231 (Figure S4e,f and Figure 4c,d) compared to MDA-MB-231 control (Figure S4d). Therefore, BCI-121 and Inhibitor-4 prompted an increase in G1 fractions. However, treatments with BCI-121 and Inhibitor-4 did not induce cell cycle arrest (Figure S4h,i) compared to control (Figure S4g) or show statistical differences in normal MCF10A cells (Figure 4e,f). 


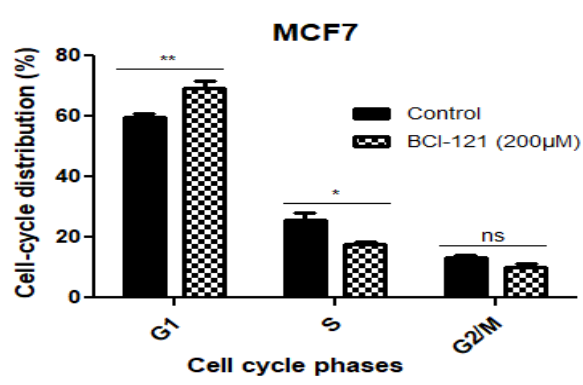

(a)

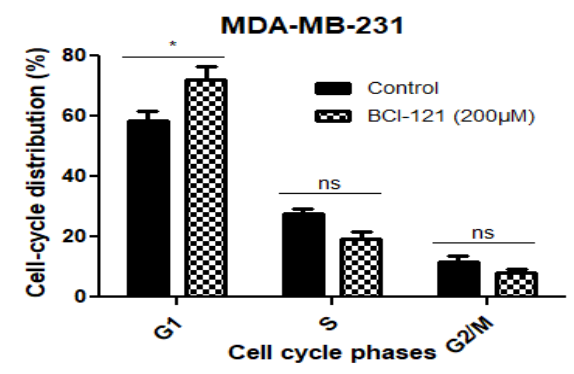

(c)

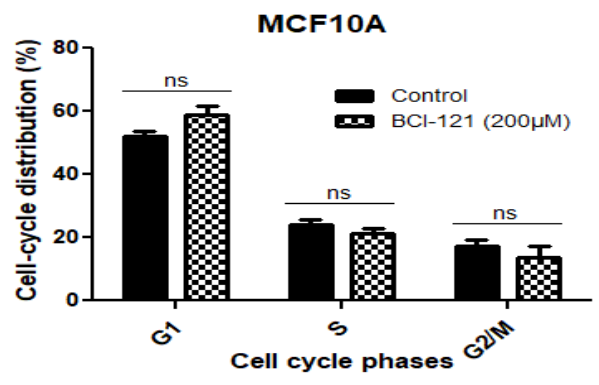

(e)

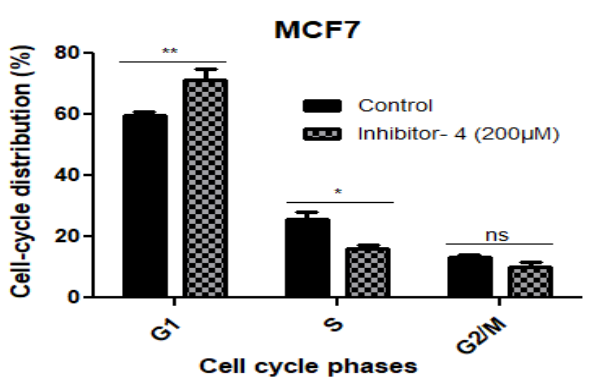

(b)

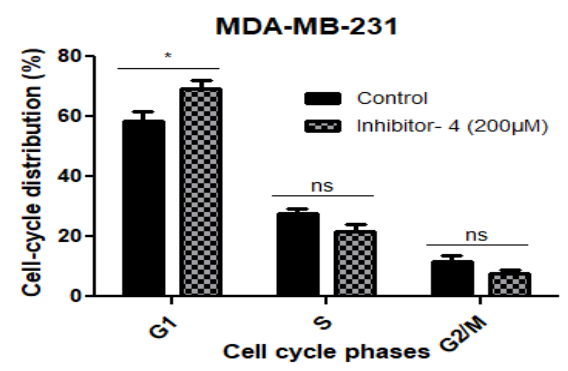

(d)

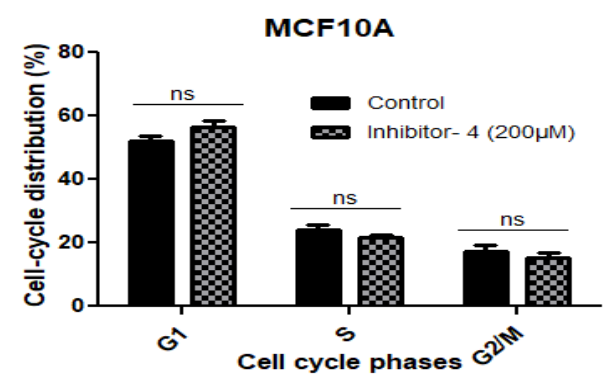

$(\mathbf{f})$

Figure 4. The cell cycle distribution was assessed using PI in MCF7, MDA-MB-231 (breast cancer cell lines) and MCF10A cells (normal breast epithelial cell line) with SMYD3 inhibitor treatments for $24 \mathrm{~h}$ and was investigated by flow cytometry. $(\mathbf{a}, \mathbf{c}, \mathbf{e})$ indicate statistical significant differences on cell cycle phases of the three cell lines treated with BCI-121. (b,d,f) show statistically significant differences on cell cycle phases of the three cell lines treated with Inhibitor- 4 . Values are mean \pm standard error of the means. Statistically significant differences from control are indicated by ${ }^{*} p<0.05,{ }^{* *} p<0.01$ or ns $p>0.05$.

\subsection{Inhibitor-4 Promotes Apoptosis in Breast Cancer Cells}

To reveal whether Inhibitor- 4 induce apoptosis on breast cancer cell line or not, we performed apoptosis assay using APC Annexin V/PI followed by flow cytometry analysis. After $48 \mathrm{~h}$ of Inhibitor- 4 treatment, the percentage of live cells decreased to $71 \%$ in both breast cancer cell lines (from $91 \%$ in MCF7 and 95\% in MDA-MB-231) as demonstrated by flow cytometry (Figure S55d,f,j,l and Figure 5b,d). Also, treatment with Inhibitor-4 showed increase in late apoptosis and necrosis percentages in MCF7 (Figure S5d,f and Figure 5b), while MDA-MB-231 showed early apoptosis with treatment of Inhibitor-4 (Figure S5j,1 and Figure 5d). BCI-121 caused late apoptosis in MCF7 and both early and late apoptosis in MDA-MB-231 cells, in addition to necrosis in MCF7 cells (Figure S5e,k and Figure 5a,c). Neither treatment caused significant differences in apoptosis nor necrosis in MCF10A cells (Figure S5q, $r$ and Figure $5 \mathrm{e}, \mathrm{f})$. 


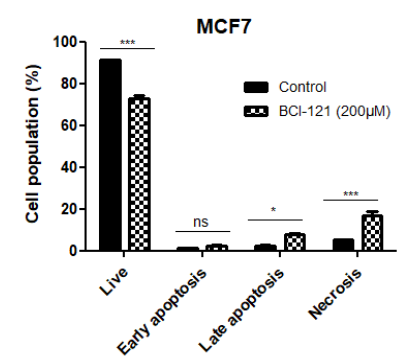

(a)

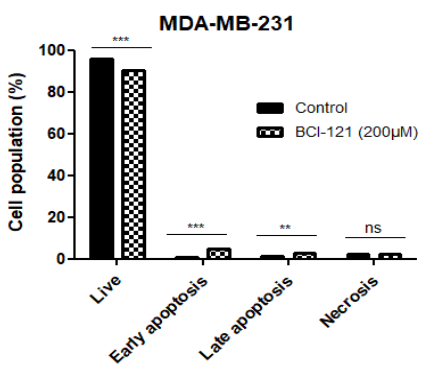

(c)

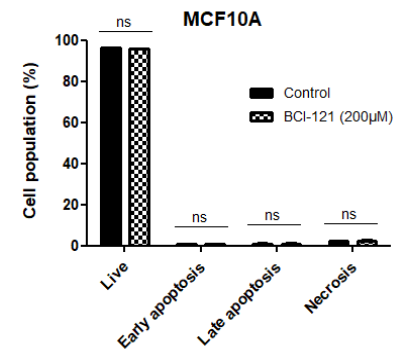

(e)

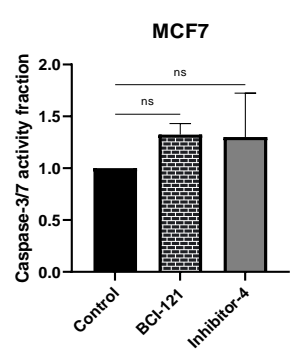

(g)

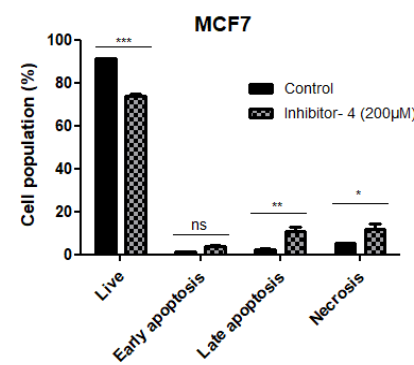

(b)

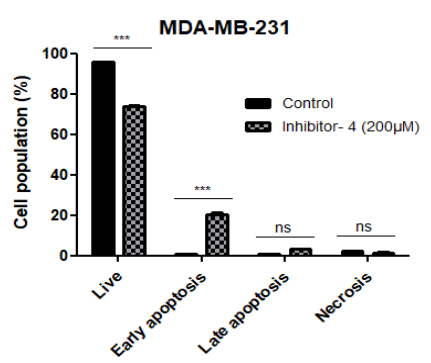

(d)

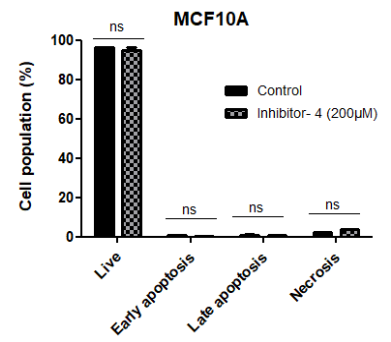

(f)

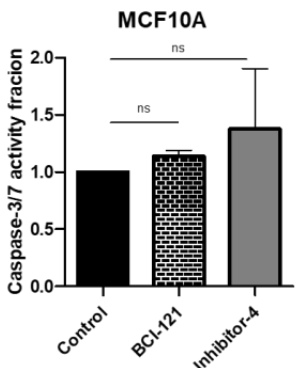

(h)

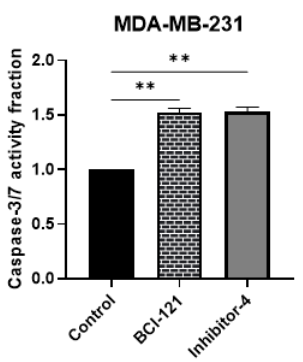

(i)

Figure 5. Cell apoptosis was assessed using APC Annexin V/PI and flow cytometry. (a,b) MCF7 (breast cancer), (c,d) MDA-MB-231 (breast cancer) and (e,f) MCF10A (normal breast) cell lines were treated with SMYD3 inhibitors for $48 \mathrm{~h}$. (a,c,e) Apoptosis after $48 \mathrm{~h}$ of BCI-121 treatment on each cell line. (b,d,f) Apoptosis after $48 \mathrm{~h}$ of Inhibitor-4 treatment on each cell line. (g-i) Cell apoptosis was investigated with SMYD3 inhibitors using Caspase-3/7 activity assay. Values are mean \pm standard error of the means. statistically significant differences from control are indicated by $p<0.05, * * p<0.01$, *** $p<0.001$ or ns $p>0.05$.

Apoptosis induction through SMYD3 inhibitors was also tested using Caspase-3/7 activity assay. The data have shown increase in Caspase-3/7 activity in MDA-MB-231, however, no significant differences in MCF7, which is Caspase-3/7 independent apoptosis pathway, and MCF10-A. 


\section{Discussion}

Aberrant expression of SMYD3 has been shown to be oncogenic and is essential for the proliferation of most colorectal, hepatocellular, and breast carcinomas, as well as prostate cancer $[3,8]$. Over 80 genes (including highly regulated homeobox genes, cell cycle regulators, and oncogenes) display altered expression because of aberrant upregulation of SMYD proteins [1-3]. Specifically, SMYD3 over-expression is highly associated with cancer development by regulating tumor proliferation, metastasis, invasion, and apoptosis [22]. Several studies have shown that SMYD3 regulates the oncogenic RAS signaling pathway by integrating a cytoplasmic-kinase signaling cascade, resulting in accelerated cell proliferation and differentiation [9]. Another study demonstrated that SMYD3 is essential for estrogen receptor-mediated transcription in breast cancer cells by down-regulating SMYD3 via RNA interference [14]. SMYD3 mediated-H2A.Z methylation has also been shown to trigger cyclin A1 gene expression, leading to cell cycle activation in breast cancer cells [23]. Knock down of SMYD3 in ovarian cancer tissues leads to upregulation of CDKN2B (p15INK4B), CDKN2A (p16INK4), CDC25A and CDKN3 as members of cyclin-dependent kinase inhibitors (CDK) [24]. Inducing apoptosis via silencing of SMYD3 has also been observed in ovarian cancer in vivo and has been accredited to the upregulation of CD40LG and downregulation of BIRC3 [24]. BIRC3 is a member of the inhibitors of apoptosis proteins (IAP) family and relates to many cancers in cases of aberrant overexpression because it can prevent apoptotic signals $[25,26]$. Therefore, it is likely that SMYD3 inhibitors can trigger apoptosis by down-regulating BIRC3. In addition, another study demonstrated that the MCF7 cell line lacks Caspase 3, which is essential for apoptosis, however in the absence of Caspase 3, Caspase 6 can be activated as an alternative mechanism to trigger apoptosis. As a result, under cellular stress, MCF7 cells undergo apoptosis in response to Caspase 6 and necrosis in response to TNF- $\alpha$ stimulation [27-29]. Despite the connection between SMYD3-overexprssion and several types of carcinogenesis, few studies have targeted SMYD3 inhibition in the context of breast cancer through the design of the inhibitors.

In this study, we sought to design small molecule inhibitors for the inhibition of SMYD3-mediated methylation (Figure 1), proliferation (Figure 3), colony formation (Figure S2), and viability (Figure S3) in breast cancer cells. Specifically, we demonstrated that in silico enzyme models can predict effective competitive enzyme inhibitors by screening vast molecular libraries and predicting binding energies. This approach to small molecule design significantly reduces the time, expense, and equipment that have been required for traditional benchtop small molecule screening until now.

Using Schrodinger ${ }^{\circledR}$ software and several in vitro assays, we demonstrated that one of the hit compounds identified in silico (Inhibitor-4) was able to reduce breast cancer cellular growth and viability without affecting normal breast epithelial cells. In vitro, Inhibitor-4 was shown to inhibit SMYD3-mediated histone methylation. In breast cancer cells, Inhibitor-4 extended cell doubling time (Figure 3). We also demonstrated that Inhibitor-4 arrests the cell cycle in breast cancer cells without affecting normal cells (Figure 4 and Figure S4), which demonstrates an improvement over BCl-121, a previously-developed SMYD3 inhibitor. Finally, the novel SMYD3 inhibitor presented here caused apoptosis in breast cancer cell lines without affecting the normal breast cell line (Figure 5 and Figure S5). However, testing the in vivo SMYD3 specificity of Inhibitor-4 needs to investigate the impacts of Inhibitor-4 on SMYD3-knockdown cells. This could be performed for future characterization and validation.

\section{Conclusions}

In conclusion, we have successfully used in silico compound screening to identify a small molecule that inhibit SMYD3 activity in vitro and reduced cancer cell growth and proliferation. Future work will involve the application of this approach to other therapeutic targets and the continued development and optimization of therapeutics for SMYD3-related cancers. 


\section{Materials and Methods}

\subsection{In Silico Screening}

We implemented the Small Molecule Drug Discovery Suite (Schrodinger, Inc., New York, NY, USA) to predict the binding affinity of a library of 137,990 molecules [15-17]. This library of molecules was downloaded from the free ZINC15 database, and included all "purchasable" molecules with reported or predicted activity in vitro [30]. The 3D structure of SMYD3 used for in silico docking was uploaded from the Protein Data Bank (PDB) under PDB identification code 5EX3 [31]. After an initial simulation which docked each molecule into SMYD3's protein-target binding pocket (not its s-adenosylmethionine binding pocket), the top ten hits (most-negative binding energy) were entered into the ZINC15 molecular similarity search engine, and the 50 most-similar compounds to each of the ten leading candidates were again scored using the Schrodinger software (500 total compounds). From this iteration, the top five compounds were purchased and assessed in vitro using SMYD3 methyltransferase assays. After initial experiments, Inhibitor-4 was found to be the most promising and, consequently, it advanced to the cell line experiments described below.

\subsection{Chemical Compounds}

All screened compounds were dissolved in dimethyl sulfoxide (DMSO) as 5, 10 or $100 \mathrm{mM}$ stock solutions. The positive control, BCI-121, is a previously-reported SMYD3 inhibitor shown to reduce the cellular proliferation of colorectal and ovarian cancer [21,24]. It was purchased from Millipore Sigma (1817, Burlington, MA, USA) and dissolved in DMSO at 10 and $100 \mathrm{mM}$. BCI-121 was used in all experiments to investigate its impacts against breast cancer cell lines and as a positive control inhibitor. All compounds were stored at $-20{ }^{\circ} \mathrm{C}$ until used for the experiments. Some $\mathrm{d}_{6}$-dimethyl sulfoxide (D, 99.9\%) containing 0.05\% v/v TMS were used for the ${ }^{1} \mathrm{H}$ NMR stability study and the $\mathrm{d}_{6}$-dimethyl sulfoxide was purchased from Cambridge Isotope Laboratories, Inc. and used as is. The stock solutions of $10.0 \mathrm{mM}$ of BCI-121 and Inhibitor- 4 were prepared immediately before use in $\mathrm{d}_{6}$-DMSO.

\subsection{In Vitro Methylation Assay}

In vitro methylation was investigated using a colorimetric assay (BioVision, K986-100, Milpitas, CA, USA). SMYD3 inhibitors (160 nM) were incubated with H3 recombinant protein (1.6 $\mu \mathrm{M}$; Sigma-Aldrich, SRP0177, St. Louis, MO, USA) for $10 \mathrm{~min}$ at room temperature. Next, SMYD3 recombinant protein (100 nM; Sigma-Aldrich, SRP0153, St. Louis, MO, USA) and s-adenosylmethionine (SAM) cofactor (500 $\mu \mathrm{M}$, methyl donor ligand) were added to the SMYD3 inhibitor and H3 solution in the methylation buffer that was provided with the kit. The absorbance was read using a microplate reader (BioTek, Cytation 5, Winooski, VT, USA) at $570 \mathrm{~nm}$ in kinetic mode every $30 \mathrm{~s}$ at $37^{\circ} \mathrm{C}$ for $45 \mathrm{~min}$. The optical density (OD) of the inhibitors was normalized to the optical density (OD) of the control [3].

\subsection{NMR Spectroscopy Analysis}

The $10.0 \mathrm{mM}$ stock solutions of Inhibitor-4 and BCI-121 were prepared freshly in $\mathrm{d}_{6}$-DMSO containing $0.05 \% v / v$ tetramethylsilane (TMS) and diluted to the final concentration of $5.0 \mathrm{mM}$ in $\mathrm{d}_{6}$-DMSO. The stabilities of Inhibitor- 4 and BCI-121 were determined by $1 \mathrm{D}^{1} \mathrm{H}$ Nuclear Magnetic Resonance (NMR) spectroscopy on a Bruker $400 \mathrm{MHz}$ NMR spectrometer at $25{ }^{\circ} \mathrm{C}$ using routine parameters [32]. 2D-NMR experiment will run to confirm the assignments (data not included) [32]. Chemical shifts were measured against TMS (0 ppm) as an internal reference. The spectra of Inhibitor- 4 and BCI-121 were recorded at 0 and $24 \mathrm{~h}$. The spectra were worked up and integrated using Mnova V.14 (MestreLab Research SL, Escondido, CA, USA). The signals in the aromatic region were used to measure the ratio of starting material and hydrolysis product. 


\subsection{Cell Culture}

All cells were purchased from ATCC and cultured according to manufacturer recommendations. The human breast epithelial cell line MCF10A (ATCC CRL-10317, Manassas, VA, USA) was used as a normal cell line and grown in DMEM/F12 (Invitrogen, 11330-032, Carlsbad, CA, USA) supplemented with 5\% horse serum (Invitrogen, 16050-122, Carlsbad, CA, USA), 1\% antibiotic/antimycotic mixture (Millipore Sigma, A5955, Burlington, MA, USA), insulin (10 $\mu \mathrm{g} / \mathrm{mL})$, EGF (20 ng/mL), cholera toxin $(100 \mathrm{ng} / \mathrm{mL})$, and hydrocortisone (500 ng/mL) [33]. The mammary gland breast cancer lines MCF7 and MDA-MB-231 (ATCC HTB-22 and 26, Manassas, VA, USA) were grown in DMEM media (Corning, 29818003, Corning, NY, USA) with 10\% FBS (Atlas Biologicals, F-0500-A, Fort Collins, CO, USA) and 1\% antibiotic/antimycotic mixture (Millipore Sigma, A5955, Burlington, MA, USA) [34]. All cell lines were grown in a humidified incubator at $5 \% \mathrm{CO}_{2}$ and $37^{\circ} \mathrm{C}$ with regular passaging to avoid confluence.

\subsection{Protein Extraction and Immunoblotting}

Total protein was extracted from frozen cells using RIPA buffer (150 mM NaCl, $5 \mathrm{mM}$ EDTA, 50 Tris- $\mathrm{HCl} \mathrm{pH} 8.0,1 \% \mathrm{NP}-40,0.5 \%$ Na-catecholate and $0.1 \%$ SDS) supplemented with protease inhibitor (PI 87785, Life tech, Carlsbad, CA, USA). Protein concentration was determined according to Bradford (1976) using bovine serum albumin as a standard [35]. Fifty micrograms of total protein were separated by SDS-PAGE, transferred to nitrocellulose membrane by electroblotting as described by [36] and probed with the antibodies specific for the indicated proteins [36]. Actin was used as an internal control for normalization. Antibodies for immunoblot detection of SMYD3 (Rabbit monoclonal antibody to SMYD3, ab183498, Abcam, Cambridge, MA, USA) and $\beta$-Actin (A5316-100 UL, Sigma-Aldrich, St. Louis, MO, USA) have been used as the primary antibodies. Bound antibodies on blots were detected by HRP-conjugated secondary antibodies (ab205718, Abcam, Cambridge, MA, USA). Detection was done using Clarity Western ECL Substrate (Bio-Rad, Hercules, MA, USA) and visualized using Image Lab Software (Bio-Rad). Densitometric evaluation was performed by ImageJ software (Version 2.0.0).

\subsection{Immunocytochemistry}

Exponentially growing cells were fixed with $4 \%$ paraformaldehyde for $15 \mathrm{~min}$ at room temperature. After PBS wash, cells were permeabilized with $0.1 \%$ SDS, $0.5 \%$ Triton X-100 in PBS for $10 \mathrm{~min}$ at room temperature. $10 \%$ goat serum in PBS was used for blocking for $30 \mathrm{~min}$ at room temperature. Primary antibody was diluted in 1:300 and treated for $1 \mathrm{~h}$ at $37^{\circ} \mathrm{C}$. Secondary antibody (Alexa488 conjugated anti-rabbit IgG) was diluted for 1:500 and treated for $30 \mathrm{~min}$ at $37^{\circ} \mathrm{C}$. DAPI in Vectashield antifade solution was used for mounting. The images were capture by Zeiss Axiophot microscope with Qimaging Exi Aqua camera with Qcapture pro software. Blue signal was obtained with 50 millisecond exposure. Green signal was obtained with 200 millisecond exposure. Signals were quantified by densitometry using ImageJ2 software (Version 2.0.0).

\subsection{In Vitro Cell Growth Inhibition Assay}

Normal and breast cell lines were plated at a density of 20,000 cells/well onto a 6-well plate with different concentrations of Inhibitor-4 and BCI-121. After trypsinization, cell numbers were counted and scored as the number of proliferating cells after treatments at different time points (24, 48, 72 and 96 h) using a Coulter Counter Z2 (Beckman-Coulter Z2 Coulter Particle Count Counter and Size Analyzer, Brea, CA, USA). Data were analyzed and cell doubling time was calculated using GraphPad Prism 6 software (Graph Pad Software, La Jolla, CA, USA) through the exponential growing equation using the exponential growing stage [37]. 


\subsection{Clonogenic Cell Survival}

A colony formation assay was used to determine cell sensitivity to SMYD3 inhibitors. The self-renewal and proliferative capacities of cells were measured. To form colonies, cells were seeded onto 6 well plates and were treated with varying concentrations of BCI-121 and Inhibitor- 4 . The plated cells were incubated in a humidified incubator at $5 \% \mathrm{CO}_{2}$ and $37{ }^{\circ} \mathrm{C}$ for two weeks. Then, colonies were fixed with $100 \%$ ethanol and allowed to dry for $20 \mathrm{~min}$ at room temperature before staining. Colonies were stained using $0.1 \%$ crystal violet and allowed to dry before counting. Reproductively viable surviving cells were counted based on the microscopic colonies containing more than 50 cells. From the cell survival fraction, survival curves were drawn using Graph Pad Prism 6 software (Graph Pad Software, La Jolla, CA, USA). At least three independent experiments for each cell line were conducted [38].

\subsection{MTT Assay}

Cells were plated at a density of 5000 cells/well in 96 well plates. After seeding, cells were treated with the vehicle (DMSO $0.1 \%, 0.15 \%$ and $0.2 \% v / v$ ) or various concentrations of the screening inhibitors. The plated cells were incubated in $\mathrm{CO}_{2}$ and treated for 24, 48, 72 and $96 \mathrm{~h}$. Then, $10 \mu \mathrm{L}$ MTT solutions $(5 \mathrm{mg} / \mathrm{mL})$ were added to each well followed by a $4 \mathrm{~h}$ incubation in $\mathrm{CO}_{2}$ in the dark. Formazan crystals formed were dissolved in $100 \mu \mathrm{L}$ of SDS followed by a second $4 \mathrm{~h}$ incubation in $\mathrm{CO}_{2}$. The absorbance was read using a microplate reader (BioTek Instrument, Cytation 5, Winooski, VT, USA). The optical density (OD) of each sample was subtracted from the optical density (OD) of the background and the Formazan standard curve was determined. Cellular viability of all samples was calculated using the ratio of the inhibitor treated-groups versus vehicle-treated group. Graph bars were obtained using GraphPad Prism 6 software (Graph Pad Software, La Jolla, CA, USA) [39].

\subsection{Cell Cycle Assay}

Cell cycle distributions were analyzed using PI flow cytometry. Cells were plated at density of $5 \times 10^{5}$ cells per well onto 6-well plate. Cells were treated with $200 \mu \mathrm{M}$ of Inhibitor- 4 or BCI-121 and incubated in a humidified incubator at $5 \% \mathrm{CO}_{2}$ and $37^{\circ} \mathrm{C}$ for $24 \mathrm{~h}$. Following incubation, detached cells were collected, washed two times with phosphate buffered saline (PBS). Then, cells were fixed with $70 \%$ ethanol in PBS overnight at $4{ }^{\circ} \mathrm{C}$. The fixed cells were washed with PBS twice to remove ethanol thoroughly. The cells were resuspended in propidium iodide staining solution consisting of $20 \mu \mathrm{g} / \mathrm{mL}$ propidium iodide and $200 \mu \mathrm{g} / \mathrm{mL}$ RNase in $0.1 \%$ Triton X-100. The stained cells were incubated for $15 \mathrm{~min}$ in an incubator at $37^{\circ} \mathrm{C}$. DNA contents were measured subsequently using CyAn ADP analyzer flow cytometry (Beckman Coulter, Fort Collins, CO, USA). Each cell line was gated at 10,000 events and the cell cycle distributions were determined using FLOWJO 10.6 software (FlowJo LLC, Ashland, OR, USA) [40].

\subsection{Apoptosis Assays}

Cell apoptosis was detected using Annexin V, which binds to translocated phosphatidylserine (PS) in the plasma membrane as previously described [41]. Necrosis and late apoptosis were detected using PI to test loss of cell membrane integrity. Briefly, cells were plated and treated with $200 \mu \mathrm{M}$ of either BCI-121 or Inhibitor-4 for 48 h. Then, the cells were washed with PBS, trypsinized, pelleted, and resuspended in Annexin binding buffer. The cells were stained first with APC Annexin V for 15 min and then with $2.5 \mu \mathrm{L}$ of PI. The cell mixture was analyzed using a Cytek 4-laser Aurora instrument (Cytek, Fremont, CA, USA). From each sample, a minimum of $3 \times 10^{4}$ events was collected. SpectroFlo software (Cytek, Fremont, CA, USA) was used to analyze the multivariate data. APC Annexin V+/PI+, APC Annexin V-/PI-, APC Annexin V+/PI- or APC Annexin V-/PI+ represented late apoptotic cells, viable cells (intact), early apoptotic cells or necrosis, respectively [42]. 
In addition to, apoptosis induction by SMYD3 treatments was also assessed using Caspase 3/7 activation. Exponentially growing cells were treated with $200 \mu \mathrm{L}$ of BC1-121 and Inhibitor-4. After $48 \mathrm{~h}$ of incubation, the early apoptosis was measured with the activation of Caspase 3/7 by Caspase-Glo 3/7 kit (Promega, Madison, WI, USA). Glow luminesce of 15,000 cells was measured by Lumat LB9507 (Berthold technologies, Oak Ridge, TN, USA).

\subsection{Statistical Analysis}

The statistical significance of the results in this study was analyzed using GraphPad Prism 6 software (Graph Pad Software, La Jolla, CA, USA) for two-way ANOVA analysis. $p$ value of less than 0.05 were considered statistically significant for all analyses.

Supplementary Materials: The following are available online at http://www.mdpi.com/1422-0067/21/24/9549/s1, Figure S1: 1H NMR spectra, Figure S2: Clonogenic cell survival curve, Figure S3: Cell viability using MTT assay, Figure S4: The cell cycle distribution, Figure S5: Cell apoptosis.

Author Contributions: I.M.A., D.K.J., H.M.I., D.C.C., T.A.K., and M.A.B. designed the research. I.M.A., D.K.J., Z.A., K.N.H., J.M., A.P., and H.M.I. performed research. I.M.A., D.K.J., Z.A., H.M.I., D.C.C., T.A.K., and M.A.B. analyzed the data. I.M.A., D.K.J., H.M.I., D.C.C., T.A.K., and M.A.B. wrote the manuscript. All authors have read and agreed to the published version of the manuscript.

Funding: Support for this work was provided by NSF Grant 1930417 to MAB.

Acknowledgments: The authors would like to thank the laboratory of Elizabeth P. Ryan at Colorado State University for the contribution of support and resources. The authors would also like to thank the flow cytometry core facility at Colorado State University.

Conflicts of Interest: The authors declare no conflict of interest.

\section{References}

1. Brown, M.A.; Sims, R.J.; Gottlieb, P.D.; Tucker, P.W. Identification and characterization of Smyd2: A split SET/MYND domain-containing histone $\mathrm{H} 3$ lysine 36-specific methyltransferase that interacts with the Sin3 histone deacetylase complex. Mol. Cancer 2006, 5, 26. [CrossRef] [PubMed]

2. Gottlieb, P.D.; Pierce, S.A.; Sims, R.J.; Yamagishi, H.; Weihe, E.K.; Harriss, J.V.; Maika, S.D.; Kuziel, W.A.; King, H.L.; Olson, E.N. Bop encodes a muscle-restricted protein containing MYND and SET domains and is essential for cardiac differentiation and morphogenesis. Nat. Genet. 2002, 31, 25-32. [CrossRef] [PubMed]

3. Hamamoto, R.; Furukawa, Y.; Morita, M.; Iimura, Y.; Silva, F.P.; Li, M.; Yagyu, R.; Nakamura, Y. SMYD3 encodes a histone methyltransferase involved in the proliferation of cancer cells. Nat. Cell Biol. 2004, 6, 731-740. [CrossRef] [PubMed]

4. Brown, M.A.; Foreman, K.; Harriss, J.; Das, C.; Zhu, L.; Edwards, M.; Shaaban, S.; Tucker, H. C-terminal domain of SMYD3 serves as a unique HSP90-regulated motif in oncogenesis. Oncotarget 2015, 6, 4005. [CrossRef]

5. Komatsu, S.; Imoto, I.; Tsuda, H.; Kozaki, K.-I.; Muramatsu, T.; Shimada, Y.; Aiko, S.; Yoshizumi, Y.; Ichikawa, D.; Otsuji, E. Overexpression of SMYD2 relates to tumor cell proliferation and malignant outcome of esophageal squamous cell carcinoma. Carcinogenesis 2009, 30, 1139-1146. [CrossRef]

6. Cock-Rada, A.M.; Medjkane, S.; Janski, N.; Yousfi, N.; Perichon, M.; Chaussepied, M.; Chluba, J; Langsley, G.; Weitzman, J.B. SMYD3 promotes cancer invasion by epigenetic upregulation of the metalloproteinase MMP-9. Cancer Res. 2012, 72, 810-820. [CrossRef]

7. Luo, X.-G.; Zhang, C.-L.; Zhao, W.-W.; Liu, Z.-P.; Liu, L.; Mu, A.; Guo, S.; Wang, N.; Zhou, H.; Zhang, T.-C. Histone methyltransferase SMYD3 promotes MRTF-A-mediated transactivation of MYL9 and migration of MCF-7 breast cancer cells. Cancer Lett. 2014, 344, 129-137. [CrossRef]

8. Hamamoto, R.; Silva, F.P.; Tsuge, M.; Nishidate, T.; Katagiri, T.; Nakamura, Y.; Furukawa, Y. Enhanced SMYD3 expression is essential for the growth of breast cancer cells. Cancer Sci. 2006, 97, 113-118. [CrossRef]

9. Mazur, P.K.; Reynoird, N.; Khatri, P.; Jansen, P.W.; Wilkinson, A.W.; Liu, S.; Barbash, O.; Van Aller, G.S.; Huddleston, M.; Dhanak, D. SMYD3 links lysine methylation of MAP3K2 to Ras-driven cancer. Nature 2014, 510, 283-287. [CrossRef] 
10. Liu, C.; Fang, X.; Ge, Z.; Jalink, M.; Kyo, S.; Björkholm, M.; Gruber, A.; Sjöberg, J.; Xu, D. The telomerase reverse transcriptase (hTERT) gene is a direct target of the histone methyltransferase SMYD3. Cancer Res. 2007, 67, 2626-2631. [CrossRef]

11. Zou, J.-N.; Wang, S.-Z.; Yang, J.-S.; Luo, X.-G.; Xie, J.-H.; Xi, T. Knockdown of SMYD3 by RNA interference down-regulates c-Met expression and inhibits cells migration and invasion induced by HGF. Cancer Lett. 2009, 280, 78-85. [CrossRef] [PubMed]

12. Ren, T.-N.; Wang, J.-S.; He, Y.-M.; Xu, C.-L.; Wang, S.-Z.; Xi, T. Effects of SMYD3 over-expression on cell cycle acceleration and cell proliferation in MDA-MB-231 human breast cancer cells. Med. Oncol. 2011, 28, 91-98. [CrossRef] [PubMed]

13. Kunizaki, M.; Hamamoto, R.; Silva, F.P.; Yamaguchi, K.; Nagayasu, T.; Shibuya, M.; Nakamura, Y.; Furukawa, Y. The lysine 831 of vascular endothelial growth factor receptor 1 is a novel target of methylation by SMYD3. Cancer Res. 2007, 67, 10759-10765. [CrossRef]

14. Kim, H.; Heo, K.; Kim, J.H.; Kim, K.; Choi, J.; An, W. Requirement of histone methyltransferase SMYD3 for estrogen receptor-mediated transcription. J. Biol. Chem. 2009, 284, 19867-19877. [CrossRef]

15. Friesner, R.A.; Murphy, R.B.; Repasky, M.P.; Frye, L.L.; Greenwood, J.R.; Halgren, T.A.; Sanschagrin, P.C.; Mainz, D.T. Extra precision glide: Docking and scoring incorporating a model of hydrophobic enclosure for protein-ligand complexes. J. Med. Chem. 2006, 49, 6177-6196. [CrossRef] [PubMed]

16. Greenwood, J.R.; Calkins, D.; Sullivan, A.P.; Shelley, J.C. Towards the comprehensive, rapid, and accurate prediction of the favorable tautomeric states of drug-like molecules in aqueous solution. J. Comput. Aided Mol. Des. 2010, 24, 591-604. [CrossRef] [PubMed]

17. Shelley, J.C.; Cholleti, A.; Frye, L.L.; Greenwood, J.R.; Timlin, M.R.; Uchimaya, M. Epik: A software program for $\mathrm{pK}$ a prediction and protonation state generation for drug-like molecules. J. Comput. Aided Mol. Des. 2007, 21, 681-691. [CrossRef]

18. Liu, L.; Kimball, S.; Liu, H.; Holowatyj, A.; Yang, Z.-Q. Genetic alterations of histone lysine methyltransferases and their significance in breast cancer. Oncotarget 2015, 6, 2466. [CrossRef]

19. Ma, S.-J.; Liu, Y.-M.; Zhang, Y.-L.; Chen, M.-W.; Cao, W. Correlations of EZH2 and SMYD3 gene polymorphisms with breast cancer susceptibility and prognosis. Biosci. Rep. 2018, 38. [CrossRef]

20. Van Aller, G.S.; Reynoird, N.; Barbash, O.; Huddleston, M.; Liu, S.; Zmoos, A.-F.; McDevitt, P.; Sinnamon, R.; Le, B.; Mas, G. Smyd3 regulates cancer cell phenotypes and catalyzes histone H4 lysine 5 methylation. Epigenetics 2012, 7, 340-343. [CrossRef]

21. Peserico, A.; Germani, A.; Sanese, P.; Barbosa, A.J.; Di Virgilio, V.; Fittipaldi, R.; Fabini, E.; Bertucci, C.; Varchi, G.; Moyer, M.P. A SMYD3 small-molecule inhibitor impairing cancer cell growth. J. Cell. Physiol. 2015, 230, 2447-2460. [CrossRef] [PubMed]

22. Huang, L.; Xu, A.-M. SET and MYND domain containing protein 3 in cancer. Am. J. Transl. Res. $2017,9,1$. [PubMed]

23. Tsai, C.-H.; Chen, Y.-J.; Yu, C.-J.; Tzeng, S.-R.; Wu, I.-C.; Kuo, W.-H.; Lin, M.-C.; Chan, N.-L.; Wu, K.-J.; Teng, S.-C. SMYD3-mediated H2A. Z. 1 methylation promotes cell cycle and cancer proliferation. Cancer Res. 2016, 76, 6043-6053. [CrossRef] [PubMed]

24. Jiang, Y.; Lyu, T.; Che, X.; Jia, N.; Li, Q.; Feng, W. Overexpression of SMYD3 in Ovarian Cancer is Associated with Ovarian Cancer Proliferation and Apoptosis via Methylating H3K4 and H4K20. J. Cancer 2019, 10, 4072. [CrossRef] [PubMed]

25. Deveraux, Q.L.; Reed, J.C. IAP family proteins-Suppressors of apoptosis. Genes Dev. 1999, 13, $239-252$. [CrossRef] [PubMed]

26. Kempkensteffen, C.; Hinz, S.; Christoph, F.; Köllermann, J.; Krause, H.; Schrader, M.; Schostak, M.; Miller, K.; Weikert, S. Expression parameters of the inhibitors of apoptosis cIAP1 and cIAP2 in renal cell carcinomas and their prognostic relevance. Int. J. Cancer 2007, 120, 1081-1086. [CrossRef]

27. Jänicke, R.U.; Sprengart, M.L.; Wati, M.R.; Porter, A.G. Caspase-3 is required for DNA fragmentation and morphological changes associated with apoptosis. J. Biol. Chem. 1998, 273, 9357-9360. [CrossRef]

28. Kagawa, S.; Gu, J.; Honda, T.; McDonnell, T.J.; Swisher, S.G.; Roth, J.A.; Fang, B. Deficiency of caspase-3 in MCF7 cells blocks Bax-mediated nuclear fragmentation but not cell death. Clin. Cancer Res. 2001, 7, 1474-1480. 
29. Tewari, M.; Quan, L.T.; O’Rourke, K.; Desnoyers, S.; Zeng, Z.; Beidler, D.R.; Poirier, G.G.; Salvesen, G.S.; Dixit, V.M. Yama/CPP32 $\beta$, a mammalian homolog of CED-3, is a CrmA-inhibitable protease that cleaves the death substrate poly (ADP-ribose) polymerase. Cell 1995, 81, 801-809. [CrossRef]

30. Sterling, T.; Irwin, J.J. ZINC 15-ligand discovery for everyone. J. Chem. Inf. Modeling 2015, 55, $2324-2337$. [CrossRef]

31. Fu, W.; Liu, N.; Qiao, Q.; Wang, M.; Min, J.; Zhu, B.; Xu, R.-M.; Yang, N. Structural basis for substrate preference of SMYD3, a SET domain-containing protein lysine methyltransferase. J. Biol. Chem. 2016, 291, 9173-9180. [CrossRef] [PubMed]

32. Koehn, J.T.; Magallanes, E.S.; Peters, B.J.; Beuning, C.N.; Haase, A.A.; Zhu, M.J.; Rithner, C.D.; Crick, D.C.; Crans, D.C. A synthetic isoprenoid lipoquinone, menaquinone-2, adopts a folded conformation in solution and at a model membrane interface. J. Org. Chem. 2017, 83, 275-288. [CrossRef] [PubMed]

33. Debnath, J.; Muthuswamy, S.K.; Brugge, J.S. Morphogenesis and oncogenesis of MCF-10A mammary epithelial acini grown in three-dimensional basement membrane cultures. Methods 2003, 30, 256-268. [CrossRef]

34. Roger, S.; Besson, P.; Le Guennec, J.-Y. Involvement of a novel fast inward sodium current in the invasion capacity of a breast cancer cell line. Biochim. Biophys. Acta BBA Biomembr. 2003, 1616, 107-111. [CrossRef]

35. Bradford, M.M. A rapid and sensitive method for the quantitation of microgram quantities of protein utilizing the principle of protein-dye binding. Anal. Biochem. 1976, 72, 248-254. [CrossRef]

36. Chiacchiera, F.; Matrone, A.; Ferrari, E.; Ingravallo, G.; Sasso, G.L.; Murzilli, S.; Petruzzelli, M.; Salvatore, L.; Moschetta, A.; Simone, C. p38 $\alpha$ blockade inhibits colorectal cancer growth in vivo by inducing a switch from HIF1 $\alpha$-to FoxO-dependent transcription. Cell Death Differ. 2009, 16, 1203-1214. [CrossRef]

37. Maeda, J.; Yurkon, C.R.; Fujisawa, H.; Kaneko, M.; Genet, S.C.; Roybal, E.J.; Rota, G.W.; Saffer, E.R.; Rose, B.J.; Hanneman, W.H. Genomic instability and telomere fusion of canine osteosarcoma cells. PLoS ONE 2012, 7, e43355. [CrossRef]

38. Kato, T.A.; Okayasu, R.; Bedford, J.S. Signatures of DNA double strand breaks produced in irradiated G1 and G2 cells persist into mitosis. J. Cell. Physiol. 2009, 219, 760-765. [CrossRef]

39. Van Meerloo, J.; Kaspers, G.J.; Cloos, J. Cell sensitivity assays: The MTT assay. In Cancer Cell Culture; Springer: Berlin/Heidelberg, Germany, 2011; pp. 237-245.

40. Krishan, A. Rapid flow cytofluorometric analysis of mammalian cell cycle by propidium iodide staining. J. Cell Biol. 1975, 66, 188-193. [CrossRef]

41. Vermes, I.; Haanen, C.; Steffens-Nakken, H.; Reutellingsperger, C. A novel assay for apoptosis flow cytometric detection of phosphatidylserine expression on early apoptotic cells using fluorescein labelled annexin $\mathrm{V}$. J. Immunol. Methods 1995, 184, 39-51. [CrossRef]

42. Aubry, J.P.; Blaecke, A.; Lecoanet-Henchoz, S.; Jeannin, P.; Herbault, N.; Caron, G.; Moine, V.; Bonnefoy, J.Y. Annexin V used for measuring apoptosis in the early events of cellular cytotoxicity. Cytom. J. Int. Soc. Anal. Cytol. 1999, 37, 197-204. [CrossRef]

Publisher's Note: MDPI stays neutral with regard to jurisdictional claims in published maps and institutional affiliations.

(C) 2020 by the authors. Licensee MDPI, Basel, Switzerland. This article is an open access article distributed under the terms and conditions of the Creative Commons Attribution (CC BY) license (http://creativecommons.org/licenses/by/4.0/). 